\title{
Effects of Dopamine Implanted in the Median Eminence on the Estrous Cycle of the Rat
}

\author{
HaRuko UEMURA AND Hideshi KOBAYASHI \\ Misaki Marine Biological Station, University of Tokyo, Misaki, Kanagawa
}

\begin{abstract}
Synopsis
A mixture (DA-C) of dopamine hydrochloride and cholesterol in a ratio of 2 to 1 or 5 to 1 by weight was implanted into different hypothalamic regions of the rat and allowed to persist for more than two weeks. The estrous cycles and ovarian histology were examined to determine effects of the treatment. When the tip of the cannula containing DA-C (2 to 1 ) hit the posterior median eminence (ME) and a small part of the arcuate nucleus (AN), the rats showed prolonged estrus. The ovaries of these rats showed big follicles and no corpora lutea. When the tip of the cannula of DA-C (5 to 1) hit the posterior $\mathrm{ME}$ and a small part of the $\mathrm{AN}$, the rats showed prolonged diestrus. The follicles and corpora lutea were small in the ovaries of these rats. Under our experimental conditions, DA seems to inhibit LH and FSH release at the level of the ME. When the tips of the cannulae containing DA-C were placed in $\mathrm{AN}, \mathrm{n}$. ventromedialis, $\mathrm{n}$. premamillaris ventralis, $n$. premamillaris dorsalis, $n$. dorsomedialis pars ventralis or adenohypophysis, the rats showed cycles with or without minor irregularities.
\end{abstract}

Using electron microscopy, several investigators have identified small granules having diameters of about $1000 \mathrm{~A}$ in the external layer of the tetrapod median eminence (for reviews see Kobayashi and Matsui, 1969; Kobayashi et al., 1970). Kobayashi (1964) first suggested on morphological grounds that these granules are probably carriers of monoamines. Independently, Carlsson et al. (1962), Falck (1964) and Fuxe (1964) have shown with a specific fluorescence method that monoamines, especially dopamine (DA), are concentrated in the external layer of the rat median eminence. Several investigators have recently employed similar fluorescence techniques to examine the median eminence of other species of animals (Akmeyev and Donáth, 1965; Lichtensteiger and Langemann, 1966; Sano et al., 1967; Odake, 1967; Björklund et al., 1968a, b; Fuxe and Hökfelt,

Received for publication February 19, 1971.
1967, 1969; Sharp and Follett, 1968). Furthermore, there are two reports showing DA and noradrenaline determined chemically in the mammalian median eminence (Laverty and Sharman, 1965; Iwata and Ishii, 1969). In addition to these findings, we have histochemically demonstrated that monoamine oxidase is concentrated in the external layer of the avian and mammalian median eminence (Matsui and Kobayashi, 1965; Follett et al., 1966; Urano, 1968). These observations led us to explore what physiological roles the monoamines might perform in the median eminence. As one method of approaching this problem, DA was implanted into the median eminence, into other hypothalamic regions and into the adenohypophysis of the rat. Effects of the DA were examined in relation to gonadotropin secretion as judged by changes in the estrous cycle. Preliminary reports concerning monoamine implantation have already been published elsewhere (Matsui, 1967; 
Kobayashi and Ishii, 1969; Kobayashi and Matsui, 1969; Kobayashi, 1970; Kobayashi et al., 1970).

\section{Material and Methods}

Fourty-eight female Wistar rats $(250-300$ g) showing a 4-day cyclicity in their estrous cycles were used. All rats were housed in an air-conditioned room at about $20^{\circ} \mathrm{C}$ with controlled lighting (12-hr light and 12-hr darkness) and supplied with commercial food and water ad libitum.

Dopamine hydrochloride (DA) and cholesterol (C) were mixed in a small amount of ether in a ratio of 2 to 1 or 5 to 1 by weight and then dried. It was shown in preliminary tests that these concentrations of DA are effective and that they do not damage the brain tissue. About $5 \mathrm{mg}$ of cholesterol alone or of the mixture (DA-C) was tamped into steel cannulae with an outside diameter of $0.9 \mathrm{~mm}$. Since the effects of implanted DA continued for at least 40 days, calculated amounts of DA absorbed from the cannulae by the nervous tissues are about $80 \mu \mathrm{g}$ on an average per day in DA-C (2 to 1$)$ and $100 \mu \mathrm{g}$ in DA-C (5 to 1$)$. The cannula containing cholesterol or DA-C was implanted stereotaxically into the brain of the anaesthetized rats with Nembutal. Before implantation, the external surface of the cannula was cleaned with ether to remove any excess material on it and the tip was covered by a film of sucrose. The following procedures were employed in order to place the tip of the cannula correctly into the median eminence. The dorsal half of the skull was removed immediately after killing the rat and the third ventricle was opened. After a samll piece of lead was inserted into the median eminence or the adenohypophysis, the ventricle was closed again and the skull was replaced. Then, the rat was firmly fixed to a stereotaxic unit, to make antero-posterior and lateral X-ray exposures. The locations of the lead on the films were recorded in relation to the positions of the third ventricle, the presphenoid, basisphenoid bones and the suture between them.

Before the implantation, the rat was anesthetized and firmly fixed to the stereotaxic instrument. Then, the cannula was fixed to the instrument. On the basis of the coordinates determined above, the cannula was lowered to a position on the skull, which was directly over the desired postition in the brain. Anteroposterior and lateral X-ray exposures were then made and the films were developed immediately to verify its postition of the tip of the cannula or to provide the basis for adjustment when necessary. After two horizontal coordinates were adjusted, a small opening was made in the skull with a dental drill. Then, the cannula was lowered into the brain so that the tip was placed in the desired position. After the cannula was lowered, it was fixed securely to the skull with dental resin and two anchoring screws. Two X-ray exposures were made again to provide a record of the postition of the tip of the cannula in the brain. Then, the upper portion of the cannula which was outside the resin, was cut off after the rat was freed from the stereotaxic instrument.

The rats implanted with DA-C (2 to 1$)$ were killed between 31 and 40 days after the implantation. The rats implanted with DA-C (5 to 1) were killed between 15 and 18 days after the implantation. In both experiments, the rats implanted with cholesterol served as controls. In the other experiment, the cannula of DAC (5 to 1) was implanted into the adenohypophysis. Intact rats served as controls. Cannulae containing cholesterol were not implanted into the adenohypophysis. The vaginal smear was recorded every day from about 10 days before the operation to the day of killing the rats. Body weights were determined at the time of operation and then at intervals of 4 to 6 days during the experimental period. Ovaries, thyroids, adrenals and pituitaries were weighed at autopsy and fixed in Bouin's fluid. The hypothalamic region was dissected out and fixed in Bouin's fluid. The ovaries and pituitaries were embedded in paraffin, sectioned at $10 \mu$, and stained with Delafield's haematoxylin and eosin. The hypothalamic tissues were embedded in paraffin, sectioned at $15 \mu$ and stained with toluidine blue 0 . The loci of the cannula tips in the adenohypoplysis and in the hypothalamus were examined microscopically with reference to the rat brain atlas (König and Klippel, 1963).

\section{Results}

\section{Body weight}

The rats implanted with cholesterol in the median eminence including a small part of the arcuate nucleus (AN) showed a decrease in body weight by 10 to $30 \mathrm{~g}$ soon after the implantation. About one week after the operation, they began to gain weight, and it returned to the initial value between 2 and 4 weeks after the implantation. The body weight of the rats implanted with DA-C of both concentrations showed similar body weight changes to those of the cholesterol control rats. The body weight of the rats implanted with DA-C (5 to 1 ) in the adenohypophysis 


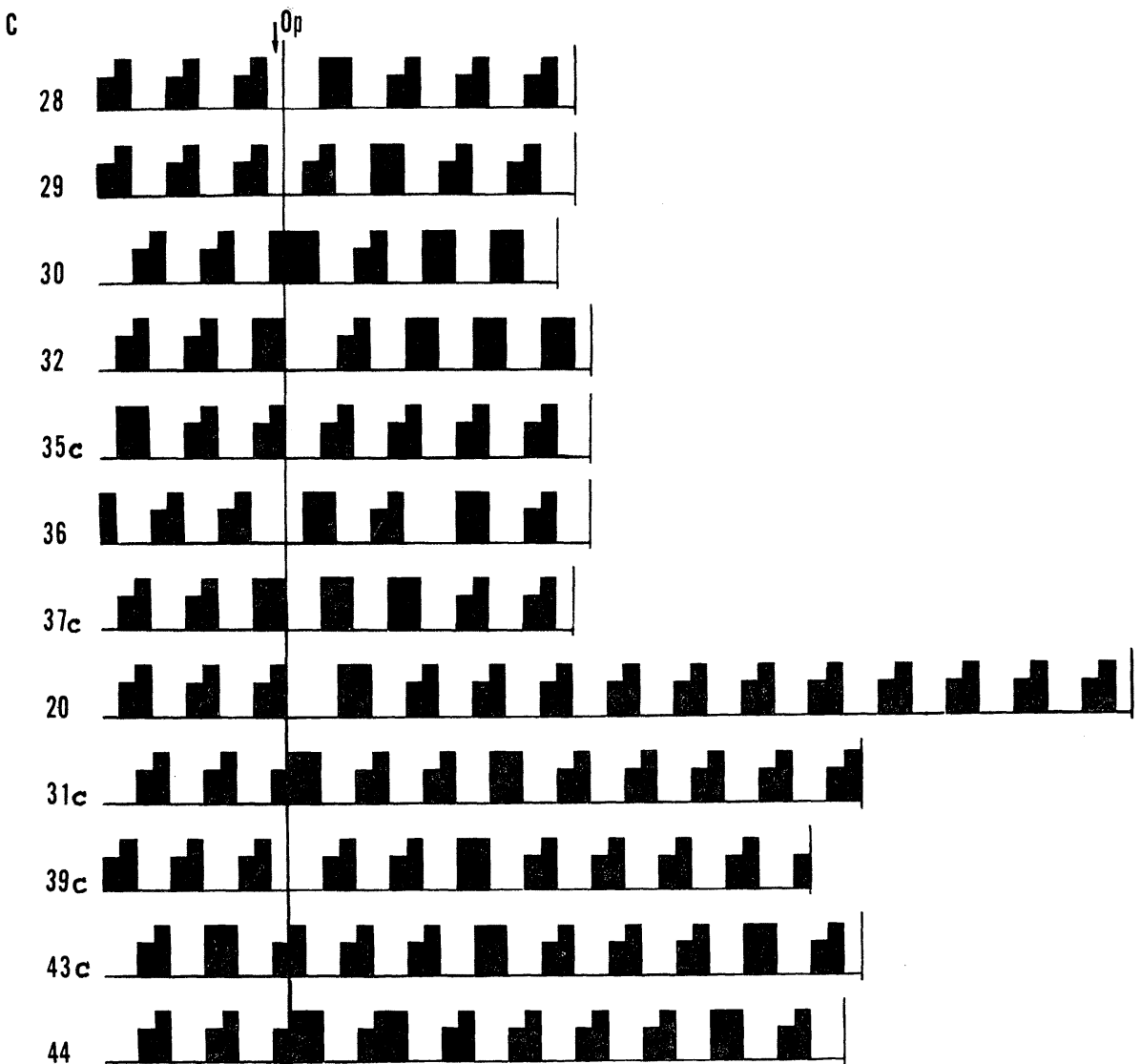

Fig. 1. Estrous cycles of the rats receiving implants of cholesterol in the median eminence. The tallest black bar represents estrus and the shorter one proestrus. The white space between the black bars indicates diestrus. The rat number is shown at the left side of the figures. Op, date of operation.

decreased by 9 to $25 \mathrm{~g}$ soon after the operation, and it returned to the initial level within two weeks.

\section{Estrous cycle and ovary}

Twelve control rats implanted with cholesterol alone had apparently normal ovaries and showed regular estrous cycles, wherever the implants were located in the hypothalamus including the median eminence. Figure 1 shows the estrous cycles of the rats bearing cholesterol implants in the median eminence and AN.

In two rats (Fig. 2; Nos. 8 and 13) implanted with DA-C (2 to 1) in the exact posterior median eminence including a small part of the AN showed prolonged estrus with occasional intermittent diestrus for more than one month until the time of killing. The ovarian weight was half that of control rats (Table 1). The follicles were not numerous but those present were large or cystic. There were no corpora lutea. The interstitial tissue was relatively abundant (Fig. 3), compared with that of control rats (Fig. 4). In two rats (Fig. 2; Nos. 5 and 6), the tip of the cannula containing $\mathrm{DA}-\mathrm{C}(2$ to 1$)$ was in the AN near the posterior median eminence. In the other two rats (Fig. 2; Nos. 10 and 11), the implants hit unilaterally AN near the posterior median eminence, 


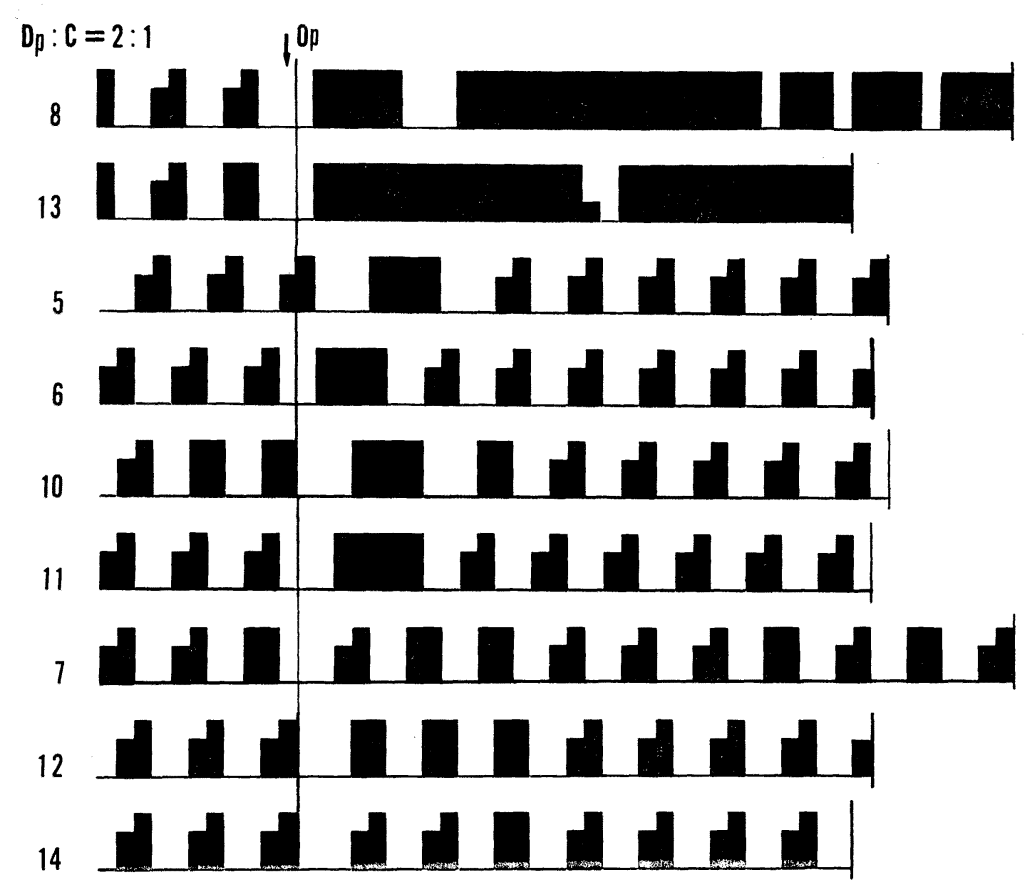

Fig. 2. Estrous cycles of the rats receiving implants of a mixture of dopamine and cholesterol (2 to 1 ) in the posterior median eminence (Nos. 8, 13), in AN near the median eminence (Nos. 5, 6, 1011 ), or in the posterior part of AN and other nuclei (see text) (Nos. 7, 12, 14).

n. ventromedialis (HVM), n. premamillaris ventralis $(\mathrm{PV})$, n. premamillaris dorsalis (PD) and $\mathrm{n}$. dorsomedialis pars ventralis (HDV). These four rats remained in estrus for 4 to 5 days and then went into diestrus for 2 to 3 days soon after the implantation; after this they showed regular estrous cycles (Fig. 2). The weights of the ovaries of these four rats were normal at the end of the experiments (Table 1), when the estrous cycle was normal (Fig. 2).

The rat (Fig. 2; No. 7) implanted with DA-C (2 to 1$)$ unilaterally in the AN posterior to the median eminence and the PV showed normal estrous cycles. In two rats (Fig. 2; Nos. 12 and 14), the tip of the cannula hit unilaterally the AN posterior to the median eminence, HDV, PV, and in addition HVM in No. 14. In these three rats the ovarian weight (Table 1) and histology were not different from control animals, and the estrous cycle was regular (Fig. 2).
In the experiments using DA-C (5 to 1 ), three rats (Fig. 6; Nos. 31, 40 and 45) had the tip of the cannula hitting the posterior median eminence and a small part of the AN. These rats showed prolonged diestrus with intermittent estrous periods. The ovarian weight of these three rats was smaller than that of the cholesterol control rats (Table 1). The follicles and corpora lutea were smaller than those in the ovaries of the control group (Fig. 5).

In five rats (Fig. 6; Nos. 33, 35, 38, 39 and 43), the cannula tip was placed unilaterally in a small part of the $\mathrm{AN}$ and in a small lateral extension of the posterior median eminence. The estrous cycles of these rats were slightly irregular, but not grossly abnormal. The weight and histology of the ovaries did not differ from those of the controls at the end of the experiment (Table 1).

When the tip was placed only in a small part of the AN near the median eminence in two 
Table 1. Organ weights $(\mathrm{mg})$ of the rats receiving implants of mixtures of dopamine and cholesterol in hypothalamus

\begin{tabular}{|c|c|c|c|c|c|c|c|}
\hline & $\begin{array}{l}\text { Material } \\
\text { implanted }\end{array}$ & $\begin{array}{c}\text { Site of } \\
\text { implantation }\end{array}$ & $\begin{array}{c}\text { Rat } \\
\text { number }\end{array}$ & Ovary & Thyroid & Adrenal & Pituitary \\
\hline \multirow{4}{*}{$\begin{array}{l}\text { Long term } \\
\text { experiment }\end{array}$} & $\begin{array}{l}\text { Cholesterol } \\
\text { (control) }\end{array}$ & $\begin{array}{l}\text { Median } \\
\text { eminence } \\
\text { and } \mathrm{AN}^{\mathrm{a}}\end{array}$ & $\begin{array}{l}20,33 c, 39 c \\
43 c, 44\end{array}$ & $\begin{array}{l}67.7 \pm \\
4.11(5)^{b}\end{array}$ & $\begin{array}{l}17.17 \pm \\
1.586(4)\end{array}$ & $\begin{array}{l}71.1 \pm \\
3.88(5)\end{array}$ & $\begin{array}{l}9.73 \pm \\
0.542(5)\end{array}$ \\
\hline & \multirow{3}{*}{$\begin{array}{l}\text { DA-C } \\
(2 \text { to } 1)\end{array}$} & $\begin{array}{l}\text { Posterior } \\
\text { median } \\
\text { eminence } \\
\text { and AN }\end{array}$ & 8,13 & $\begin{array}{l}36.0,35.0 \\
(2)^{* * *}\end{array}$ & $16.85(1)$ & $\begin{array}{l}78.0 \\
66.0(2)\end{array}$ & $\begin{array}{l}12.90 \\
11.90(2)^{*}\end{array}$ \\
\hline & & $\begin{array}{l}\text { Immediately } \\
\text { above } \\
\text { median } \\
\text { eminence }\end{array}$ & $5,6,10,11$ & $\begin{array}{l}60.0 \pm \\
2.07(4)\end{array}$ & $\begin{array}{l}17.90 \pm \\
1.538 \stackrel{(4)}{(4}\end{array}$ & $\begin{array}{l}60.3 \pm \\
2.15(4)\end{array}$ & $\begin{array}{l}10.00 \pm \\
1.890(3)\end{array}$ \\
\hline & & $\begin{array}{l}\text { Postericr to } \\
\text { median } \\
\text { eminence }\end{array}$ & $7,12,14$ & $\begin{array}{l}70.2 \pm \\
4.75(3)\end{array}$ & $\begin{array}{l}15.75 \\
19,35(2)\end{array}$ & $\begin{array}{l}69.0 \pm \\
9.36(3)\end{array}$ & $\begin{array}{l}9.70 \pm \\
0.475(3)\end{array}$ \\
\hline \multirow{4}{*}{$\begin{array}{l}\text { Short term } \\
\text { experiment }\end{array}$} & $\begin{array}{l}\text { Cholesterol } \\
\text { (control) }\end{array}$ & $\begin{array}{l}\text { Median } \\
\text { eminence } \\
\text { and AN }\end{array}$ & $\begin{array}{l}28,39,30, \\
32,35 c, 36, \\
37 \mathrm{c}\end{array}$ & $\begin{array}{l}70.9 \pm \\
2.69(7)\end{array}$ & $\begin{array}{l}14.74 \pm \\
0.622(7)\end{array}$ & $\begin{array}{l}72.2 \pm \\
3.24(7)\end{array}$ & $\begin{array}{l}9.08 \pm \\
0.229(7)\end{array}$ \\
\hline & \multirow{3}{*}{$\begin{array}{l}\text { DA-C } \\
(5 \text { to } 1)\end{array}$} & $\begin{array}{l}\text { Posterior } \\
\text { median } \\
\text { eminence } \\
\text { and AN }\end{array}$ & $31,40,45$ & $\begin{array}{l}54.7 \pm \\
7.65^{(3)}\end{array}$ & $\begin{array}{l}16.50 \\
16.55(2)\end{array}$ & $\begin{array}{l}68.8 \pm \\
2.17(3)\end{array}$ & $\begin{array}{l}8.19 \pm \\
0.687(3)\end{array}$ \\
\hline & & $\begin{array}{l}\text { Small part of } \\
\text { median } \\
\text { eminence } \\
\text { and AN }\end{array}$ & $\begin{array}{l}33,35,38 \\
39,43\end{array}$ & $\begin{array}{l}76.8 \pm \\
5.56(5)\end{array}$ & $\begin{array}{l}17.12 \pm \\
0.895(3)\end{array}$ & $\begin{array}{l}73.9 \pm \\
4.49(5)\end{array}$ & $\begin{array}{l}9.30 \pm \\
0.430(4)\end{array}$ \\
\hline & & $\begin{array}{l}\text { Immediately } \\
\text { above } \\
\text { median } \\
\text { eminence }\end{array}$ & 34,37 & $\begin{array}{l}79.5,74.0 \\
(2)\end{array}$ & - & $\begin{array}{l}97.5 \\
66.0(2)\end{array}$ & $\begin{array}{l}10.64,9.50 \\
(2)\end{array}$ \\
\hline
\end{tabular}

a See text for abbreviations of hypothalamic nuclei.

b Mean \pm standard error; number of animals is indicated in parentheses.

* Sigificant compared to value of cholesterol-control $(\mathrm{p}<0.05)$.

**Highly significant compared to value of cholesterol-control $(\mathrm{p}<0.01)$.

rats (Fig. 6; Nos. 34 and 37), the implant did not induce any change in the estrous cycle, ovarian weight, and ovarian histology (Table 1).

Six rats implanted with DA-C (5 to 1 ) in the pars distalis of the adenohypophysis did not show any change in the estrous cycle, ovarian weight, and ovarian histology (Fig. 7; Table 2).

\section{Weight of thyroid, adrenal and pituitary}

The thyroid glands of all the rats bearing DA-C in the hypothalamus did not show any difference in their weight from those of cholesterol control rats (Table 1). The rats implanted with DA-C did not show any change in the adrenal weight, compared with that of cholesterol control rats (Table 1). The pituitary weight of the rats (Nos. 8 and 13) implanted with DA-C (2 to 1$)$ into the posterior median eminence including a small part of the AN was greater than that of control rats. The pituitary of rats receiving implants into other regions did not differ in weight from those of controls. In the rats receiving the implants of DA-C (5 to 1$)$ in the pars distalis, the thyroid, adrenal and pituitary weights were not different from those of the untreated rats (Table 2). 


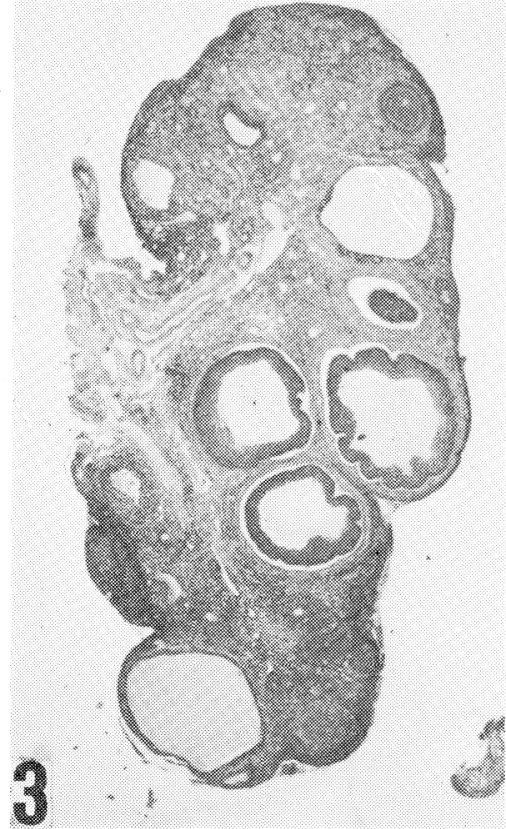

Fig. 3. Ovary of the rat (No. 8) showing prolonged estrus induced by implantation of a mixture of dopamine and cholesterol ( 2 to 1 ) in the posterior median eminence and a small part of AN.

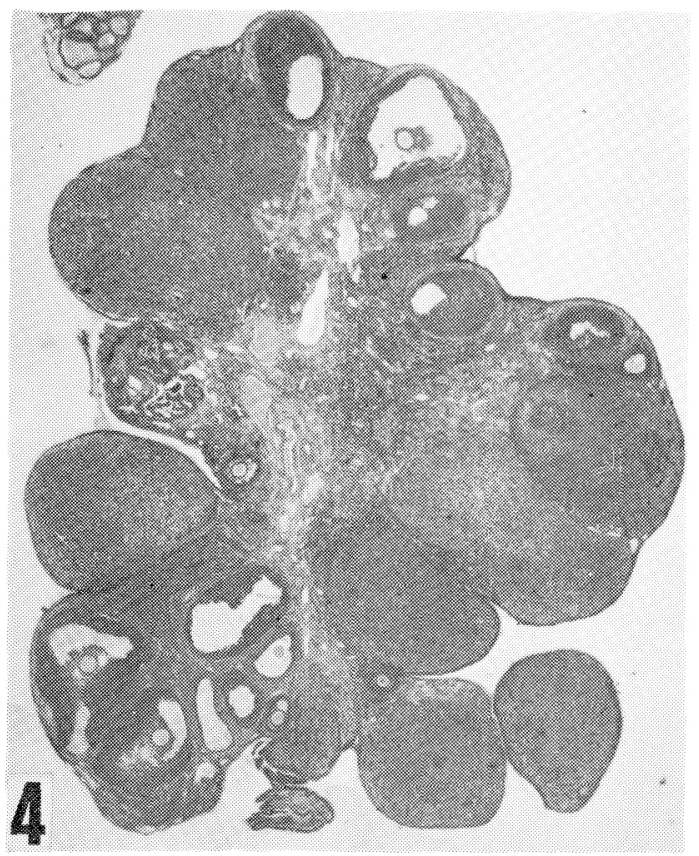

Fi.g 4. Ovary of the cholesterol control rat (No. 29) showing regular estrous cycles.

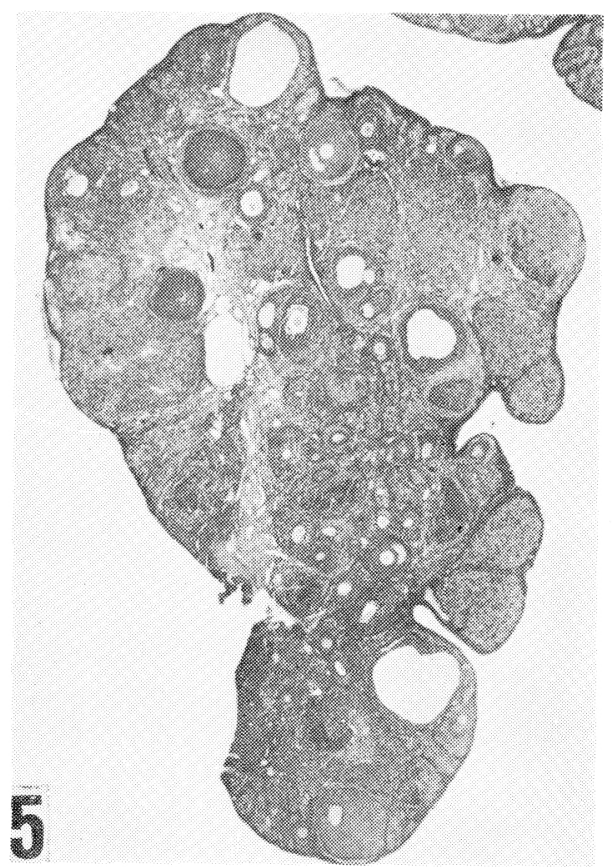

Fig. 5. Ovary of the rat (No. 31) showing prolonged diestrus right after the implantation of a mixture of dopamine and cholesterol ( 5 to 1 ) in the posterior median eminence and a small part of AN.

\section{Discussion}

Two rats (Nos. 8 and 13) implanted with DA-C (2 to 1$)$ in the posterior median eminence including a small part of the AN had large or cystic follicles and no corpora lutea, and they showed persistent estrus (Fig. 2). These findings suggest that a luteinizing hormone (LH) surge sufficient in amount for inducing ovulation was suppressed by DA and that the tonic LH release necessary for estrus with follicle stimulating hormone (FSH) was not suppressed during the period of prolonged estrus.

When the tip of the cannula containing DA-C (2 to 1) hit the regions immediately near the posterior median eminence including some nuclei (AN, HVM, PV, PD and HDV) (Nos. 5, 6, 10 and 11), the effect of DA on the estrous cycle was weaker than when it was 
Table 2. Organ weights $(\mathrm{mg})$ in the rats receiving implants of mixtures of dopamine and cholesterol (5 to 1$)$ in pars distalis of adenohypophysis

\begin{tabular}{lllll}
\hline \hline & Ovary & Thyroid & Adrenal & Pituitary \\
\hline Intact & $69.4 \pm 4.19(10)^{\mathrm{a}}$ & $16.39 \pm 0.667(8)$ & $63.1 \pm 3.28(10)$ & $8.64 \pm 0.316(9)$ \\
Experimental & $67.4 \pm 3.67(6)$ & $18.61 \pm 1.817(5)$ & $72.3 \pm 2.99(6)$ & $9.01 \pm 0.887(6)$ \\
\hline
\end{tabular}

a Mean \pm standard error; number of animals is indicated in parentheses.

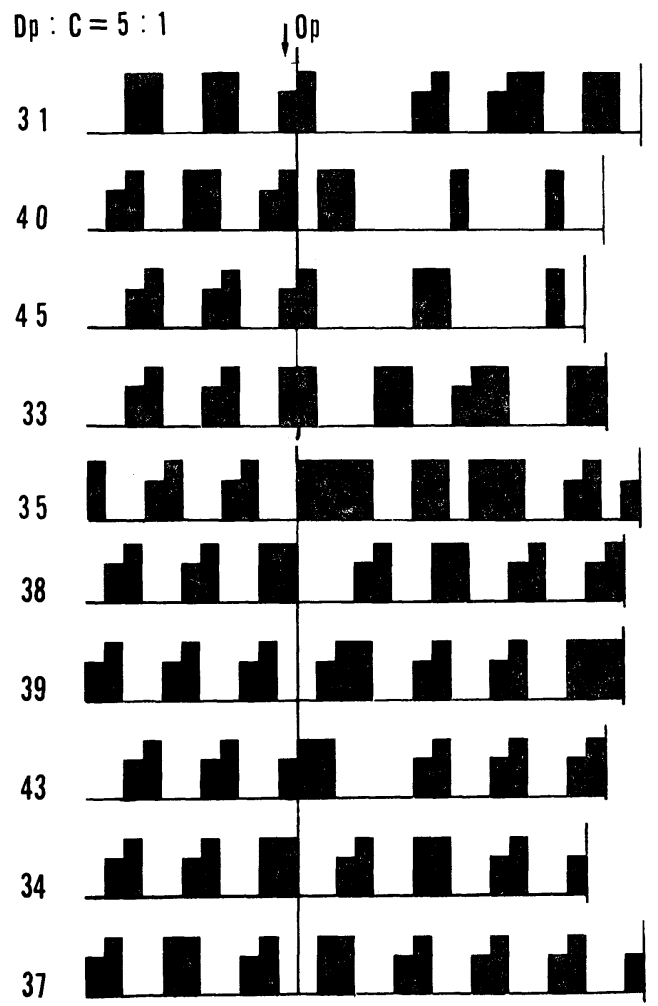

Fig. 6. Estrous cycles of the rats bearing the cannula containing a mixture of dopamine and cholesterol ( 5 to 1 ) in several hypothalamic regions (see text).

implanted exactly in the posterior median eminence (Fig. 2; Table 1). Since the rats (Nos. 7, 12 and 14) receiving implants of DA in those nuclei near the posterior median eminence did not show any change in the estrous cycle (Fig. 2; Table 1), it may be concluded that the most effective site of DA among the hypothalamic regions mentioned above appears to be the posterior median eminence.

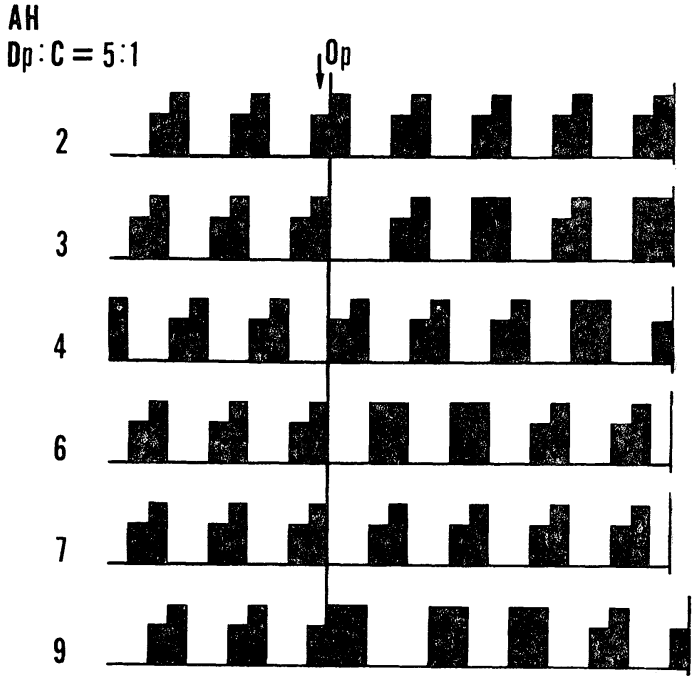

Fig. 7. Estrous cycles of the rats receiving implants of a mixture of dopamine and cholesterol ( 5 to 1 ) into the adenohypophysis.

The rats (Nos. 31, 40 and 45) receiving implants of DA-C (5 to 1 ) in the posterior portion of the median eminence with a small part of the AN showed prolonged diestrus. Since the follicles and the corpora lutea were small, it appears that in these three rats both FSH and LH release were suppressed. As mentioned above, when the cannula of DA (2 to 1) was placed in the posterior median eminence, the rats showed persistent estrus. The difference in the effects may be due to the differences in the concentrations of DA. It seems that DA-C (5 to 1) is more effective than DA-C (2 to 1 ) in suppression of gonadotropin secretion. When the cannula hit a small part of the posterior median eminence, the rats (Nos. 33, 35, 38, 39 and 43) showed slight ir- 
regularities in their estrous cycles. However, two rats (Nos. 34 and 37) bearing implants near the posterior median eminence did not show any change in the estrous cycle, unlike Nos. 5, 6, 10 and 11. Reasons for the discrepancy is not known. In any case, when the tip of the cannula was placed in posterior median eminence, the estrous cycle was greatly affected.

It has been suggested from morphological experiments that the small granules with diameters of about $1200 \mathrm{~A}$ in the axon endings of the median eminence might be carriers of gonadotropin releasing factors ( $T$. Kobayashi et al., 1963; Harris and Campbell, 1966; Zambrano and de Robertis, 1968 a, b; Zambrano, 1969; Kobayashi and Matsui, 1969; Kobayashi, et al., 1970). Furthermore, it has recently been demonstrated that those small granules separated by an ultracentrifuge from the horse median eminence show high LRF activity (Kobayashi and Ishii, 1969; Kobayashi et al., 1970; Ishii, 1970). Therefore, it is likely that in our experiments implanted DA acted on the axon endings containing LRF in the posterior median eminence, resulting in suppression of LRF release.

It is certain that the effects of DA mentioned above were not caused by its direct action on the adenohypophysis, since implantation of DA therein had no effect on the estrous cycle. In agreement with this observation, Kamberi et al. $(1970 \mathrm{a}, \mathrm{b})$ observed that perfusion of DA into the pituitary did not cause any LH release. Schneider and McCann (1969b) showed that DA had no effect on the output of LH from pituitaries incubated alone with DA, but that it enhanced LRF release from hypothalamic fragments.

The fact that DA implantation failed to alter the weights of the thyroid and adrenal glands makes it seem unlikely that disturbances in the release of gonadotropin by DA may be a consequence of interrupting the blood flow of the hypothalamo-hypophysial portal vessels. These findings also suggest that $\mathrm{DA}$ in the median eminence may not be involved in the release of thyrotropin and corticotropin releasing factors (TRF and $\mathrm{CRF}$ ) from the median eminence. In agreement with our opinion, it has been demonstrated with the fluorescence microscopical technique that DA neurons are not involved in the release of TSH and ACTH from the rat pituitary (Fuxe and Hökfelt, 1967, 1969). Smelik (1967) and Carr and Moore (1968) have also shown that brain catecholamines are not involved in stress induced ACTH release.

Our results suggest that DA in the median eminence inhibit the release of LRF. This idea agrees with the fluorescence microscopic observations by Fuxe et al. (1969) that an activation of the DA tubero-infundibular neurons, whose axons terminate in the median eminence, occurred in parallel with periods of ovulatory blockade in the rat. They have concluded that DA released from the tuberoinfundibular nucleus inhibits LRF release into the primary capillary plexus in the median eminence. Through fluorescence microscopy of the tubero-infundibular nucleus of the guinea pig Barry (1968) and Leonardelli $(1968 \mathrm{a}, \mathrm{b})$ are of a similar opinion.

However, Coppola et al. (1966) and Lippmann et al. (1967) stated that when hypothalamic catecholamines were reduced by systemic injection of some pharmacological drugs, ovulation was suppressed. Kordon and Glowinski (1969) have also shown using $\alpha$ methyl-p-tyrosine, an inhibitor of catecholamine synthesis, that DA is necessary for ovulation of the rat at a critical time of the day of proestrus. Schneider and McCann $(1969 \mathrm{a}, \mathrm{b})$ have demonstrated that DA enhanced the LRF release from the stalkmedian eminence tissue in vitro and that $\alpha$-adrenergic receptors appeared to mediate the response of the hypothalamic tissue to DA. In in vivo experiments, Schneider and McCann $(1970 \mathrm{a}, \mathrm{b})$ showed that intraventricular injection of DA induced an increase of plasma LRF, but the same doses of norepinephrine and epinephrine were less effective or not 
effective. However, Rubinstein and Sawyer (1970) have recently suggested a more specific effect of epinephrine in the triggering of ovulation than dopamine, when they were intraventricularly injected. Thus, there is still discrepancy between investigators about the effects of DA on LRF release. Furthermore, Kamberi et al. (1969) have shown that intraventricular injection of lower doses of DA induced release of $\mathrm{LH}$, but higher doses of DA inhibited the secretion of $\mathrm{LH}$ from the pituitary. However, in these experiments, site(s) of action of DA in the hypothalamus is not known exactly.

In our investigations, FSH release appeared to be suppressed at least in the rats implanted DA-C (5 to 1$)$ in the posterior median eminence and AN region, because both the follicles and corpora lutea of the ovaries were fewer and smaller. This result coincides with the opinion of Fuxe et al. (1969) deduced by fluorescence microscopy, but not with that of Kamberi et al. (1970) in which they showed that DA was effective at its appropriate concentrations in secretion of follicle stimulating hormone-releasing factor (FRF) from the stalk-median eminence tissue in vitro. On the basis of fluorescence microscopic observations, Hyppä and Lorent (1969) are of a similar opinion.

The discrepancies among investigators in DA effect on LRF and FRF release from the brain may be due to differences in their methods. First, in vitro experiments, the site of DA action in stalk-median eminence tissue is not known. Similarly, region(s) affected by intraventricularly administered DA is not known. In our experiment, DA did affect the median eminence and the most responsive site to DA was the posterior median eminence; our results are the reverse of those obtained by other investigators both in in vitro and intraventricular injection experiments. Second, differences in DA concentration may be other reasons for the discrepancies. For example, Kamberi et al. (1970) obtained reversed effects of DA on $\mathrm{LH}$ release between lower and higher concentrations. In our experiments, it is presumed that about 80 to $100 \mathrm{mg}$ on an average per day of DA are absorbed from the cannula. This amount of DA may be suppressive in LRF release. An alternative idea is that DA may be inhibitory when it is applied to the median eminence, but DA may be stimulatory if it is applied both to the median eminence and other hypothalamic regions, which were not involved in our experiments, as is expected in the in vitro and intraventricular injection experiments. Third, the various investigators have employed different criteria for evaluating LH secretion. As mentioned above, some investigators assessed $\mathrm{LH}$ secretion through the observations on ovulation, whereas others assessed it by measuring the amount of $\mathrm{LH}$ liberated in vitro. In the former way, they cannot detect minute amounts of $\mathrm{LH}$ and in the latter it is not known whether enough $\mathrm{LH}$ is released to induce ovulation or not. Fourth, the experimental periods are different among investigators.

Although we observed inhibitory effects of DA on the LRF and FRF, it is not known whether these phenomena have physiological meaning or not. Obviously, more work is needed to resolve the apparent discrepancies among the investigators.

\section{References}

Akmayev, I. G. and T. Donáth (1965). Z. mikro.-anat. Forschung 74, 83.

Barry, J. (1968). C. R. Soc. Biol. 162, 449.

Björklund, A., B. Falck and L. Ljunggren (1968a). Z. Zellforsch. 89, 193.

Björklund, A., A. Enemar and B. Falck (1968b). Ibid. 89, 590.

Carlsson, A., B. Falck and N. Ă. Hillarp (1962). Acta Physiol. Scand. 56, Suppl. 196.

Carr, L. A. and K. E. Moore (1968). Neuroendocrinology 3, 285.

Coppola, J. A., R. G. Leonardi and W. Lippmann (1966). Endocrinology 78, 225. 
Falck, B. (1964). Prog. Brain Res. 8, 28.

Follett, B. K., H. Kobayashi and D. S. Farner (1966). Z. Zellforsch. 75, 57.

Fuxe, K. (1964). Ibid. 61, 710.

Fuxe, K. and T. Hökfelt Neurosecretion (edited by S. Stutinsky). Springer Verlag, Berlin, p. 165 (1967).

Fuxe, K. and T. Hökfelt Frontiers in Neuroendocrinology (edited by W. F. Ganong and L. Martini). Oxford Univ. Press, London and New York, p. 47 (1969).

Fuxe, K., T. Hökfelt and O. Nilsson (1969). Neuroendocrinol. 5, 257.

Harris, G. W. and H. J. Campbell The Pituitary Gland, Vol. 2 (edited by G. W. Harris and B. T. Donovan). Butterworth, London and Washington, p. 99 (1966).

Hyyppä, M. and M. Lorentz (1969). Acta Endocrinol. (Kbh). Suppl. 138, 192.

Ishii, S. (1970) Endocrinology 86, 207.

Iwata, T. and S. Ishii (1969). Neuroendocrinology 5, 140.

Kamberi, I. A., R. S. Mical and J. C. Porter (1969). Science 166, 388.

Kamberi, I. A., R. S. Mical and J. C. Porter (1970 a). Endocrinology 87, 1.

Kamberi, I. A., H. P. G., Schneider and S. M. McCann (1970 b). Ibid. 86, 278.

Kobayashi, H. Proc. 2nd Intern. Congr. Endocrinol., Excerpta Med. Found. Intern. Congr. Ser. 83, Pt. 1, 570. (1964).

Kobayashi, H. La Photoregulation des Cycles Sexuels chez les Oiseaux et les Mammifères (edited by J. Benoit and I. Assenmacher). Colloq. Int. C. N. R. S. No. 172, Paris, p. 193 (1970).

Kobayashi, H. and S. Ishii (1969). Proc. 3rd Intern. Congr. Endocrinol., Excerpta Med. Med. Found. Intern. Congr. Ser 184, 548.

Kobayashi, H. and T. Matsui Frontiers in Neuroendocrinology (edited by W. F. Ganong and L. Martini) Oxford Univ. Press, London and New York, p. 3 (1969).

Kobayashi, H., T. Matsui, and S. Ishii (1970). Intern. Rev. Cytol. 29, 281.
Kobayashi, T. T. Kobayashi, K. Yamamoto, and M. Inatomi (1963). Endocrinol. Japon. $10,69$.

König, J. F. R. and R. A. Klippel The Rat Brain. The Williams and Wilkins Company, Baltimore (1963).

Kordon, C. and J. Glowinski (1969). Endocrinology 85, 924.

Laverty, R. and D. F. Sharman (1965). Brit.J. Pharmacol. 24, 538.

Leonardelli, J. (1968 a). C. R. Soc. Biol. 162, 1937.

Leonardelli, J. (1968 b). Ibid. 162, 1956.

Lichtensteiger, W. and H. Langemann (1966). J. Pharmacol. exp. Therap. 151, 400.

Lippmann, W., Leonardi, R. G., Ball. J. and J. A. Coppola (1967). Ibid. 156, 258.

Matsui, T. (1967). Annot. Zool. Jap. 40, 74.

Matsui, T. and H. Kobayashi (1965). $Z$. Zellforsch. 68, 172.

Odake, G. (1967). Ibid. 82, 46.

Rubinstein, L. and C. H. Sawyer (1970). Endocrinology 86, 988.

Sano, Y., G. Odake and S. Taketomo (1967). Neuroendocrinology 2, 30.

Schneider, H. P. G. and S. M. McCann (1969 a). Endocrinology 85, 121.

Schneider, H. P. G. and S. M. McCann (1969 b). J. Reprod. Fertil. 18, 178.

Schneider, H. P. G. and S. M. McCann (1970 a). Endocrinology 86, 1127.

Schneider, H. P. G. and S. M. McCann (1970 b). Ibid. 87, 249.

Sharp, P. J. and B. K. Follett (1968). Z. Zellforsch. 90, 245.

Smelik, P. G. (1967). Neuroendocrinology 2 , 247.

Urano, A. (1968). J. Fac. Sci. Univ., Tokyo, Sec. IV 11, 437.

Zambrano, D. and E. de Robertis (1968 a). Z. Zellforsch. 87, 409.

Zambrano, D. and E. de Robertis (1968 b). Ibid. 90, 230.

Zambrano, D. (1969). Ibid. 93, 560. 